\title{
Teachers' Satisfaction: Implications for Job Performance
}

\author{
Jhupa Kumari Budhathoki \\ jhupabc77@yahoo.com \\ Lecturer \\ Central Department of Education, T.U., Kirtipur
}

\begin{abstract}
The main objective of this study is to explore the teachers' satisfaction and their implications on job performance in schools. This study is based on a qualitative phenomenological research design and the study focused on perspectives of teachers' job satisfaction. Secondary data analysis is used and analyzed qualitatively with critical review. In educational sector, teachers are the individuals, who deliver an effective contribution in imparting knowledge, attitudes, development of skills and abilities, leading to overall growth and development of the students and welfare of the community. They are professional and ethical in their job performance. It is vital for the teachers to be satisfied with their job in order to perform their duties up to the required standard. Results show that a lack of resources, lack of dynamic leadership, overcrowded classes, lacks of discipline among learners, work overload, low salary, administrative issues, and lack of recognition by principals, job security, lack of professional opportunities, and parents for good work done were serious sources of dissatisfaction among teachers. The findings, implications from this study include offering specific professional development suggestions, as well as critical way for further examining teachers'motivation to learn as a research topic and theoretical construct.
\end{abstract}

Keywords: Teacher' job satisfaction, job performance, professional opportunities, motivation and leadership.

\section{Introduction}

Teachers are meant to not only train the students in terms of academic concepts but also values, so that they become responsible members within their family and community. There are certain factors that influence the performance and job satisfaction of the teachers in schools. Under the influence of these factors, they may either perform their job duties with carefulness and enthusiasm or they may leave their jobs. Hence, the factors have both negative as well as positive influences upon the performance and job duties of the teachers. Similarly, it is related to the teacher's motivation and active participation in teaching-learning activities in the classroom, responsibility and accountability of school (Ekpoh and Eze, 2015). 
Teacher performance and school development depends upon the characteristics of the teachers. These include their dedication, knowledge, and academic skills (Gikunda, 2016). On the other hand, working environmental conditions, terms and relationships with employers, colleagues and students, salary and remuneration, teaching-learning processes, instructional strategies and how they perform their job duties, there are number of factors that influence their job satisfaction. When recruitment takes place of teachers within the educational institutions, there are certain aspects, which need to be taken into account, these include, the educational qualifications, years of experience, personality traits and effectiveness in the performance of job duties (Chamundeswari, 2013). Teachers are a very important group of professional's chaos nation's education sector. This makes education to be one very important factor in socio-economic development of any country, hence a priority to most governments. Teachers, as human capital, impart knowledge more efficiently and even the best of facilities cannot be substituted for the teachers' roles as these facilities require well-trained instructors to make good use of them (Ahindukha, 2005). Therefore, human capital is very crucial and forms an important input in the education system that has an effect on the school performance, and if teaching is going to attract the best teachers, then it is important that factors that can divert good teachers from their profession be understood.

According to Locke (1983), job satisfaction is the pleasurable emotional state of feeling resulting from the perception of one's job as fulfilling or allowing the fulfillment of one's important job values. This is reported by people's perceptions of their work and working conditions. Lawler (1973) as cited in Sergiovanni (1995) views job satisfaction as an individual's affective relations to his work role and is a function of the perceived relationship between what one wants from one's job and what one perceives it is offering. Brady (2001) concurs with Lawler and defines job satisfaction as an emotional, affective response derived from one's job. These feelings are not limited to salary, but can also include factors like the way employees are treated and valued by management and the degree to which the company takes their input into consideration. Long \& Swortzel (2007), defined job satisfaction as any combination of psychological, physiological and environmental circumstances that cause a person to say that he/she is satisfied with his/her job.

Many teachers today, as exposed in a research carried out by Bishay (1996), are dissatisfied with their jobs and it is crucial that researchers determine how to remove these dissatisfies as well as finding ways on how to increase teacher satisfaction. Teacher job satisfaction has a crucial influence on students, teachers, and schools. Highly satisfied teachers have more positive relationships with students and are more likely to help them achieve higher academic outcomes (Dinham \& Scott, 2002; Michaelowa \& Wittmann, 2007). For teachers, the level of job satisfaction affects their involvement, commitment, and motivation (Sargent \& Hannum, 2005), work enthusiasm (Chen, 2007), and self-growth (Van den Berg, 2002). Compared with their peers, highly satisfied teachers are more likely to stay in their schools and keep on working in their teaching jobs. Therefore, exploring teacher job satisfaction is not only helpful for improving student outcomes, teaching performance, and achieving school effectiveness but also helpful for understanding the reasons for teacher migration and retention in schools.

Newstrom (2007) describes it as the particular views of employees, which are affected by the favorable and unfavorable feelings and attachments of one's work. Job satisfaction shows a 
Teachers'Satisfaction: Implications for Job Performance / 81

positive and significant link between workplace environment, the mental and physical wellbeing of employees, including the indoor environment (Veitch, Charles, Farley \& Newsham, 2007; Decroon, Sluiter, Kuijer \& Frings-Dresen, 2005; Wells, 2000). Consequently, teachers are entirely blamed for lower students' performance without comprehending the factors influencing teachers and teacher effectiveness. In fact, teacher effectiveness does not depend only on the teachers. Therefore, the main objective of this study is to explore the teachers' satisfaction and their implications on job performance in schools. Thus, the purpose of this study is to explore and analyze the job satisfaction and performance of community school teachers in Nepal. The research focused "how does the job satisfaction affect the encouragement, involvement and commitment of community school teachers in Nepal?" This study has surfaced the job satisfaction and its affect in the performance of community school teachers in Nepal.

\section{Methods of the study}

This study adopted a qualitative approach, with in secondary process depth study and reviewed of different national and international literatures, documents, journals articles as the main method of researching the phenomenon of experiences, feeling and perception of school teachers. The study used a case study design. The study was involved in exploring and analyzing the job satisfaction and performance of community school teachers in Nepal, therefore, qualitative method was considered and to accomplish this research, I conducted a review-based empirical study. Hence, secondary document analysis instrument also implies a data analysis approach concurrently in this study. The data were collected through the intensive reading of those studies and analyzed qualitatively with critical review and reflection.

\section{Result and Discussion}

In this chapter is discussed about perspectives on teacher job dissatisfaction and satisfaction, causes of teacher job dissatisfaction and influencing factors of teachers' job satisfaction and performance. The major findings were summarized and presented using descriptive way. This study was consistence with reviewed related literature document, articles, and journals as the reviewed the job satisfaction and performance of Nepalese community school's teachers through the Herzberg et al. (1959)'s two-factors theory. The result showed that community school teachers have a high dissatisfaction towards their job. Dissatisfaction of teachers determines their job performance. The results of this study are summarized linking with different related literatures.

The results showed that most of teaches were highly dissatisfied to their job. In the initial phase of job (new appointed teachers), teachers felt a highly satisfaction to their job. Relief teachers and internal sources teachers (Internal Source teachers means the teachers whose salary is bared/ paid by school's own internal income and sources, but not government. These terms are used in Nepalese Schools.

\section{Perspectives on Teacher Job Dissatisfaction and Satisfaction}

Job dissatisfaction is by definition unpleasant, and most individuals are conditioned, probably even biologically-driven, to respond to unpleasant conditions by searching for mechanisms to reduce dissatisfaction (Okeke \& Dlamini, 2013; Afshar \& Doosti, 2016). This drive towards adaptation is as natural and expected in the workplace as it is in any other environment (Chan, 
2002). Prior theory and research suggest that employees respond to job dissatisfaction in one of the four ways: exit, voice, loyalty and neglect. Firstly, and consistent with the turnover literature (Farrell, 2000), dissatisfied employees may quit an organization altogether in response to their job dissatisfaction (exit). Secondly, dissatisfied employees may choose to remain in their organization and actively try to improve conditions, actively searching for and coming up with new ways of doing things also advocating changes to make things better (voice). Thirdly, employees may remain in the organization but respond passively to their job dissatisfaction by accepting the status quo without raising any objections or making any suggestions for improvement (loyalty). Lastly, employees may remain in the organization and exhibit passive withdrawal behaviors such as putting forth less effort (neglect) (Wambugu \& Busienei, 2015).

General dissatisfaction was expressed with regard to their physical working conditions. The teachers referred to poor facilities, absence of maintenance, serious water shortage, and poor roads leading to the rural schools. It was mentioned that the roads were particularly bad when it rained. They also referred to electricity problems and the unkempt school environments. The surroundings included dilapidated buildings; tall grass and overgrown undergrowth that made the schools look unpleasant (Okeke \& Dlamini, 2013). Earlier studies (Dlamini, Okeke \& Mammen, 2014; Afshar \& Doosti, 2016), pointed out that positive work environment was very important for the workers physical, mental and emotional health. According to Khan (2003), favorable working conditions would boost teacher's job satisfaction. Iwu \& Iwu (2013) observed that a lack of adequate infrastructure was a major factor that inhibited the effective management of schools. Low teacher satisfaction is expected to correlate with the outcomes of work stress, that is, psychological distress and low self-esteem (Okeke, Adu, Drake \& Duku, 2014; Gu, 2016; Shumba, Maphosa, Rembe, Okeke \& Drake, 2016 b).

The discussion of literatures dissatisfied employees may quit an organization altogether in response to their job dissatisfaction. Dissatisfied employees may choose to remain in their organization and actively try to improve conditions, actively searching for and coming up with new ways of doing things also advocating changes to make things better. Employees may remain in the organization but respond passively to their job dissatisfaction by accepting the status quo without raising any objections or making any suggestions for improvement. Lastly, employees may remain in the organization and exhibit passive withdrawal behaviors such as putting forth less effort.

\section{Causes of Teacher Job Dissatisfaction}

The retention of teachers has been a very challenging phenomenon, but also in many different education systems across the globe (Naseem \& Salman, 2015). Dissatisfaction has been deduced by researchers as posing a major challenge for the retention of teachers and other workers (Calitz, Roux, \& Strydom, 2014). Such a scenario appears to make threats the agentive roles of teachers for social transformation in schools and larger society. Gkolia, Belias \& Koustelios (2014) have noted that teachers who are satisfied with their jobs usually have a high degree of professional capabilities and feel that they could manage, organize and perform task. A class size is not only a function; it is also dependent on the number of physical infrastructure units, such as the capacity of the classrooms to accommodate teachers and the subjects on offer. Given these scenarios, it is 
Teachers'Satisfaction: Implications for Job Performance / 83

vital to deal with issues of job dissatisfaction through an empirical study that is aimed at further exploring this particular phenomenon.

\section{Influencing factors of teachers' job satisfaction and performance}

According to Kapur (2018) the main factors that influence the teachers' job satisfaction and performance are as follows:

Teaching skills: The main job duty of the teachers is to teach students. The number of factors that need to be taken into consideration in the possession of teaching skills, include, adequate knowledge of the academic concepts, fluency in language, and implementation of those methods that are understandable by the students. The teachers are able to contribute towards learning of students and gain job satisfaction, when they possess appropriate teaching skills and abilities.

Knowledge and information: Knowledge and information are essential aspects for enhance job satisfaction. Teacher need to be skilled and proficient while working in the laboratory. It is the responsibility of the teachers to ensure that students are well equipped with complete knowledge and information, so that they do not experience any unfavorable effects. When teachers are competent and possess adequate knowledge and information, then they gain job satisfaction.

Usage of technology: In the present existence, it is vital for the teachers to possess adequate knowledge regarding usage of technology. As the meaning of the teaching-learning processes and academic concepts is only identified, when one is completely aware of usage of technology. It is vital for the teachers to possess adequate knowledge of technology in order to perform their job duties well and incur job satisfaction.

Seminars and workshops: The organization of seminars and workshops in schools are regarded as important aspects that contribute in inculcation of knowledge and generation of awareness among the individuals in terms of particular topics. The teachers either give speeches or make presentations, which enable the students to acquire better understanding of the concepts. The feelings of job satisfaction occur among the teachers, when they are given the opportunities of making presentations and speeches or participating in any functions like organizing, managing, controlling, directing, leading and co-coordinating.

Giving ideas and suggestions: The principal is vested with the authority to introduce innovative and advanced methods and strategies. But they may take ideas and suggestions from the teachers and other members of the school. They are vested with the leadership skills and authority to make important decisions. When they consult the teachers regarding any issue or problem, then in some cases, they give appropriate ideas and suggestions, which may prove to be beneficial.

Inculcation of morality and ethics among individuals: The teachers not only impart knowledge in terms of academic concepts to the students, but they are also meant to inculcate the traits of morality and ethics among them. The traits of honesty, decency, truthfulness and honesty are essential, when individuals are carrying out any kinds of tasks and functions. When the students are ethical and moral, then teachers feel pleasurable and incur job satisfaction. 
Working environmental conditions: The working environmental conditions are regarded important in influencing the job satisfaction of the teachers. Within the working environment the number of factors include, provision of adequate space, classrooms, teaching learning materials, equipment, restrooms, clean drinking water, heating and cooling equipment in accordance to the weather conditions. When individuals find there is availability of all the required materials, then they are able to perform their job duties well and acquire job satisfaction. The availability of resources is regarded as an important factor that enables the individuals to sustain job satisfaction (Gikunda, 2016).

Conflict resolution methods: In some cases, conflicting situations or disagreements do take place among the individuals, working together. They may take place among colleagues or even among superiors and subordinates. When one is unable to implement proper conflict resolution methods, then one usually hinders ones terms and relationships with others. On the other hand, when one possesses adequate knowledge regarding how to come to a conclusion peacefully, then one is able to perform ones job duties well and incur job satisfaction.

Helpfulness and co-operation: The traits of helpfulness and co-operation, not only help the individuals in performing their job duties well, but they are able to acquire appreciation and respect from the students as well as other members of the school. When a teacher is helpful and co-operative in nature, he or she is retained with the school and is given promotional opportunities and increase in salary. With these qualities, teachers are able to please the other individuals within the school environment.

Salary and reimbursements: Salary and reimbursements are regarded as essential aspects for which individuals are engaged in jobs. When the teachers feel that their salaries are sufficient enough for the sustenance of their living conditions, then they feel satisfied with their jobs.

Reward and compensation: Reward and compensation are given to the individuals within the employment settings in case of any valuable work done by them. In schools, teachers are rewarded usually when they have been within the job for a long term, when they have been enthusiastically dedicated towards the performance of job duties, possess adequate knowledge of the academic concepts, is helpful and co-operative with the other members of the school, including the principal and possess the traits of morality and ethics. The provision of reward and compensation are regarded as essential in incurring job satisfaction.

Promotional opportunities: Promotional opportunities are referred to the opportunities that lead to promotion of the individuals to an upper level. They enable the individuals to move towards advancement and growth (Nyange, 2013). These are implemented on the basis of their experience, job duties, possession of knowledge, skills and abilities and terms and relationships that they have established with the other individuals.

Distance of school from home: Research has indicated that teachers feel satisfied with their jobs, when their school is located close to their homes. When it is located at a walking distance, then the teachers just walk down and they do not have to make use of transportation facilities, 
whether it is public or personnel transportation. The teachers save lot of time, when the schools are located close to their homes. Hence, teachers are satisfied with their jobs.

Autonomy: When the teachers are allowed to make use of their own skills and abilities in the implementation of tasks and when they are permitted to exercise their autonomy, then they incur the feelings of job satisfaction.

Training: Teachers also need to upgrade their knowledge. It is essential for them to acquire adequate training regarding usage of technology. The training of the teachers either takes place through organization of workshops in schools, or they may join a training centre or they may learn the techniques from their colleagues, friends or family members. The reason being, one is able to bring about improvements in job performance.

Kapur (2018) states the influencing factors on teachers' job performance are: competency, use of teaching materials, use of teaching method, monitoring the student's work, controlling the class, participation in school activities, loyalty and integrity, counselors and guides, management and regulation, conflict resolution, school and classroom environment, confidence building, communication skills, tolerance and acceptance, research activities and time management. Similarly, it is related to their output or result of their delegated work which is improved through teaching practices, professional development, professional competition and motivation, principal's leadership role and school environment (Ghavifekr and Ibrahim, 2014).

\section{Conclusion}

The findings of this study indicate job satisfaction among school level teachers was satisfied in their occupation especially in teaching profession. Basically focus of this short-term qualitative study was to gain insights into the experiences, feeling and perceptions of school teachers in Nepal as to their job satisfaction and its affect in the performance. The study concludes that teacher satisfaction is useful for the school effectiveness and development. Positive work environment is very important for teacher's job satisfaction. Lack of adequate infrastructure was a major factor that inhibited the effective management of schools. Low teacher satisfaction is expected to correlate with the outcomes of work stress, that is, psychological distress and low self-esteem. In particular, the satisfaction of teachers must be taken very seriously. There is a close connection between the performance and job satisfaction of the teachers. When the teachers are satisfied with all the aspects within their workplace, only then they would be able to provide a significant contribution in efficiently performing their job duties.

\section{Implication of the study}

This study provides worthwhile information to improve teacher job satisfaction and performance. The appraisal of job dissatisfies and teaching related stress and their effects on job satisfaction are critical considerations for the long-term well-being of teachers, for teaching effectiveness and good student performance, and for the design and implementation of intervention programs designed to ensure quality work life for teachers. 
The literature suggests that low levels of job satisfaction result in physical and emotional illness, undesirable professional behavior and impaired job performance. Today's students are an exacting and intense endeavor, teaching performance requires competent, committed and energetic professionals. Concentrated attention should be given to ensuring work conditions that support superior teacher performance. Emphasizing a focus on the rewards of "working with students" and strengthening opportunities for collegial affiliations will continue to foster positive teacher job satisfaction. Eliminating, to the extent possible, arduous tasks and responsibilities, conducting activities to promote respect and support for teachers, providing opportunities for meaningful decision-making, ensuring written and oral administrative recognition of teachers, and creating an environment that underscores the management and elimination of stress also will enhance positive satisfaction.

\section{References}

Afshar, H.S. \& Doosti, M. (2016). Investigating the impact of job satisfaction/dissatisfaction on Iranian English teachers' job performance. Iranian Journal of Language Teaching Research, 4(1), 97-115.

Ahindukha, K. (2005). Factors, Trends and effects of teacher attrition on students' enrolment and performance in secondary schools in Kisumu city Kenya. Master of Education Thesis, Maseno University, Kenya.

Bishay, A. (1996). Teacher motivation and job satisfaction: A study employing the experience sampling method. Dartmouth College: New Hampshire - Hanover.

Brady, D.B. (2001). Correlates of job satisfaction among California School principals. Dissertation-University of Southern California: L.A-California.

Calitz, T., Roux, A. \& Strydom, H. (2014). Factors that affect social workers job satisfaction, stress and burnout. Social Work, 50(2), 153-169.

Chamundeswari, S. (2013). Job satisfaction and performance of school teachers. International Journal of Academic Research in Business and Social Sciences, 3(5), 420-428.

Chan, D.W. (2002). Stress, self-efficacy, social support, and psychological distress among prospective Chinese teachers in Hong Kong. Educational Psychology, 22(5), 557-569.

Chen, W. (2007). The structure of secondary school teacher job satisfaction and its relationship with attrition and work enthusiasm. Chinese Education and Society, 40(5), 17-31.

De Croon, E.M., Sluiter, J.K., Kuijer, P.P.F.M., \& Frings-Dresen, M.H.W. (2005). The effect of office concepts on worker health and performance: A Systematic review of the literature. Ergonomics, 48(2), 119-134.

Dinham, S. \& Scott, C. (2002). The international teacher 2000 project: An international study of teacher and school executive satisfaction, motivation and health in Australia, England, USA, Malta and New Zealand. Paper presented at the Challenging Futures Conference, University of New England, Armidale. 
Ekpoh, U.I. and G.B. Eze, 2015. Principals' supervisory techniques and teachers' job performance in secondary schools in Ikom education zone, cross river state, Nigeria. Br. J. Educ., 3: $31-40$.

Gikunda, M.G. (2016). Factors Influencing Teacher Performance in the Implementation of Geography Curriculum in Public Secondary Schools in Imenti South Sub County.

Gkolia, A., Belias, D. \& Koustelios, A. (2014). Teachers' job satisfaction and self efficacy: A review. European Scientific Journal, 10(22), 321-342.

Gu, X. (2016). Teacher job satisfaction in public schools: The relation to the years of teaching experience. Unpublished master's dissertation. New York: State University of New York.

Herzberg, F., Mausner, B., \& Snyderman, B. B. (1959). The motivation to work. New York, NY: John Wiley \& Sons.

Kapur, R. (2018). Factors influencing performance and job satisfaction of teachers in Secondary Schools in India. Publication: https://www.researchgate. net/publication/325035669.

Khan, T. (2003). Teacher Job Satisfaction and Incentive: A Case Study of Pakistan Retrieved16 August2016,fromhttp://datatopics.worldbank.org/hnp/files/edstats/

Lawler, E.E. (1973). Motivation in Work Organizations. Monterrey, CA: Brooks/Cole.

Long, J. L., \& Swortzel, K. A. (2007). Factors influencing job satisfaction of extension agents in the Mississippi State University Extension Service. Proceedings of the 2007 American Association for Agricultural Education Research Conference, 34, 41 - 53. Retrieved from http://aaaeonline.org/allconferences1.php?show_what=National\&sorter_conf= ational\&sorter_yea $\mathrm{r}=2007$

Locke, E.A. (1983). The nature and causes of job satisfaction. In M.D. Dunnette (Eds), Handbook of industrial and organizational psychology. Chicago: Rand, McNally.

Michaelowa, K., \& Wittmann, E. (2007). Cost, satisfaction, and achievement of primary education evidence from Francophone Sub-Saharan Africa. Journal of Development Areas, 41(1), 51-78.

Naseem, I. \& Salman, M. (2015). Measuring the job satisfaction level of the academic staff. Journal of Business \& Financial Affairs, 4(2), 1-6.

Newstrom, J.W. (2007). Organizational behaviour-human behaviour at work (Eds.). New York: McGraw Hill International Edition.

Okeke, C.I.O. \& Dlamini, S.C. (2013). An empirical study of stressors that impinge on teachers in secondary school in Swaziland. South African Journal of Education, 33(1), 32-43.

Okeke, C.I.O., Adu, E.O., Drake, M.L. \& Duku, N.S. (2014). Correlating demographic variables with occupational stress and coping strategies of pre-school educators: Aliterature review. Journal of Psychology, 5(2), 143-154. 
Sergiovanni, T.J. (1995). The principalship: A reflective practice perspective

Van den Berg, R. (2002). Teachers' meanings regarding educational practice. Review of Educational Research, 72, 577-625.

Wambugu, T.W. \& Busienei, J.R. (2015). Factors leading to job satisfaction of public secondary school teachers in Nairobi County, Kenya. The Strategic Journal of Business \& Change Management, 2(122), 1988-2008.

Wells, M.M. (2000). Office clutter or meaningful personal displays: The Role of office personalization in employee and organizational well-being. Journal of Environmental Psychology, 20, 239-255. 